\title{
PSICOLOGIA: uma ciência de contrastes
}

Psychology: a science of contrasts

Kairon Pereira de Araujo Sousa ${ }^{1}$

RESUMO: Esse artigo tem como objetivo discutir a questão da diversidade de objetos e métodos na psicologia. Para tanto, procuraremos reconstruir sintaticamente a história da psicologia, desde sua relação com a filosofia até sua constituição como ciência. Feito isso, mencionaremos as principais diferenças entre as escolas psicológicas, propondo por fim a reflexão da seguinte questão: é possível uma unidade nessa ciência?

Palavras-chave: Contraste. Escolas de pensamento. Unidade.

ABSTRACT: This article aims to discuss the issue of the diversity of objects and methods in psychology. To do so, we will try to reconstruct, syntactically, the history of psychology, from its relationship with philosophy to its constitution as a science. Having said this, we will mention the main differences between the psychological schools, finally proposing the reflection of the following question: is a unity possible in this science?

Keywords: Contrast. Schools of thought. Unity.

\section{INTRODUÇÃO}

A primeira surpresa ou admiração ao iniciarmos o curso de graduação em psicologia está na sua própria definição. Em outras palavras, na tentativa de responder de forma satisfatória a seguinte pergunta: O que é psicologia? A princípio parece ser algo simples, cuja resposta está na ponta da língua, entretanto, essa questão na psicologia é polêmica e não tão fácil de ser respondida.

Quando se pergunta: O que é biologia? Rapidamente, temos várias respostas semelhantes: "biologia é o estudo da vida". Da mesma forma: O que é sociologia?

\footnotetext{
${ }^{1}$ Bacharel em Psicologia (UESPI), pós-graduado em Saúde da Família (CEAD/UFPI). 
Muitos responderiam: "é a ciência que estuda as relações sociais". Quando se pergunta: O que é psicologia? A resposta parece não ser tão óbvia assim, ou seja, a psicologia parece não admitir uma única definição pronta, acabada e definitiva, por isso é complicado traçar uma definição a seu respeito.

Nos manuais da história da psicologia, verificaremos que a sua origem está ligada à filosofia, tendo ela surgido entre os gregos antigos, mais especificamente com os questionamentos socráticos sobre a existência humana.

Enquanto os primeiros filósofos gregos, conhecidos como pré ${ }^{2}$-socráticos, preocuparam-se com as questões relacionadas ao cosmo ou mundo à sua volta, questionando-se a respeito do princípio criador de todas as coisas da natureza, a physis grega. E cada qual, buscou definir esse princípio que dá origem ao mundo, representado pelos elementos da própria natureza, como: a água ou o úmido (Tales de Mileto), o apeíron ou ilimitado (Anaximandro), o ar (Anaxímenes), o fogo (Heráclito), os átomos (Leucipo e Demócrito). Sócrates traz à tona um novo questionamento: a existência humana. Diferentemente dos pensadores naturalistas que ficaram presos à explicação do cosmos, o filósofo procurou discutir o homem e sua existência, isto é, a discussão da physis dá lugar ao homem, porque, para Sócrates para compreender o mundo a sua volta, o homem precisava conhecer primeiramente a si mesmo, somente assim teria condições de voltar seu olhar para as questões externas a ele. Daí sua máxima: "conhece-te a ti mesmo".

Esse período posterior, conhecido como socrático ou antropológico, investe a filosofia das questões relacionadas ao homem. Filósofos como Sócrates, Platão e Aristóteles empreenderam estudos relacionados ao psiquismo humano. Desse modo, inicialmente, a psicologia desponta como o estudo da alma (etimologia da palavra).

Neste sentido, enquanto um saber ligado à tradição filosófica, ela se apresenta como um conhecimento especulativo. O que nos surpreende é que esses pensadores gregos já trabalhavam a com a conversação. Eles se utilizavam da palavra para tratar as pessoas com mental disorders, uma espécie de persuasão por meio da fala. Era uma maneira primitiva, mas, nós estudantes e profissionais da psicologia também fazemos uso da palavra no tratamento de nossos clientes. Claro, que as técnicas que empregamos hoje são muito mais sofisticadas, e além do mais, científicas.

\footnotetext{
${ }^{2}$ Esses pensadores são assim denominados, por antecederem as reflexões filosóficas de Sócrates, isto é, porque representam o primeiro momento filosófico da história, sendo anteriores a Sócrates.
} 
Como é possível observar, temos uma primeira definição para psicologia (ciência da alma). Esta era uma das grandes discussões entre os filósofos da época. Para Sócrates, por exemplo, a alma e o corpo representavam duas partes distintas. A primeira seria a sede das emoções, sensações e memória, sendo imortal. O corpo representaria a matéria, a parte material e mortal. Platão seu discípulo segue tal ideia. Já o Aristóteles destaca os três tipos de alma: a vegetativa, sensitiva e racional.

Uma grande ruptura acontece com o dualismo cartesiano, em que Descartes ${ }^{3}$ faz a diferenciação entre o corpo e a mente, destacando que o homem apresenta duas substâncias: uma material, e outra que ele chama de pensante. Para este filósofo, o corpo sem o espírito seria como uma máquina. Dessa forma, Descartes rompe com o pensamento do período medieval, segundo o qual o corpo do homem não poderia ser estudado pela ciência, pois, este é a imagem e semelhança de Deus. Isso contribuiu para um acontecimento marcante na psicologia no ano 1879, a fundação do laboratório experimental por Wundt ${ }^{4}$. Para alguns, esse foi o ponto que marca a libertação da psicologia em relação à filosofia. $E$ abre portas para que ela alcançasse o status de ciência. A essas alturas a psicologia deixa de ser o estudo da alma, para tornar-se o estudo da consciência.

\footnotetext{
${ }^{3}$ René Descartes foi um filósofo Frances do século XVIII, que enfatizava os poderes da razão, colocando-a como princípio seguro e único meio de tornar os homens livres e independentes. Descartes, a partir do seu método de dúvida metódica, decide colocar em descrédito tudo aquilo que havia admitido como verdades. Dispondo-se a aceitar como verdadeiro somente o que após, submetido à razão, mostra-se indubitável. O filósofo adota uma postura cética na busca do conhecimento verdadeiro, desejando perceber as coisas além das aparências. Nisso dúvida das informações provenientes dos sentidos, das argumentações dogmáticas, entretanto, depara-se com uma premissa que se mostra inquestionável: "[...] e, notando que esta verdade eu penso, logo existo era tão firme e tão certa que todas as mais extravagantes suposições dos céticos não seriam capazes de abalar, julguei que podia aceitá-las, [...], como o primeiro princípio da filosofia [...]" (DESCARTES, 1987, p.43).

Esse pensador supervalorizava a razão colocando-a como a possibilidade mais sólida de modificar a vida da humanidade, rompendo, desse modo, com as explicações pautadas nos mitos e crenças. Nas palavras de Aranha e Martins (2009, p.169), Descartes "ao tomar consciência como ponto de partida, abriu caminho para a discussão sobre ciência e ética, sobretudo ao enfatizar a capacidade humana de construir o próprio conhecimento".

${ }^{4}$ Wundt é considerado o fundador da psicologia científica. Com a fundação do laboratório de psicologia experimental na Universidade de Leipzig (Alemanha), Wundt empreendeu estudos e experimentos em psicofisiologia. Dedicou-se ao estudo dos processos mentais (sensação, percepção, atenção etc.), desenvolvendo como método para estudo desses fenômenos a introspecção (processo de auto-observação). Suas pesquisas foram importantes para o desenvolvimento dessa ciência, "tanto que a maior parte da história da psicologia pós-wundtiana é caracterizada pela contestação ao seu ponto de vista da psicologia, fato que não desvaloriza sua importância nem seus feitos como seu fundador" (SCHULTZ; SCHULTZ, 2009, ps.78-79).
} 
Contudo, desde a fundação da psicologia científica por Wundt, constantes debates e oposições têm se instalado na tentativa de traçar um objeto de estudo ou mesmo uma definição única para essa ciência. Nesse artigo discutiremos a questão da pluralidade de objetos e definições da psicologia.

\section{ESTRUTURALISMO}

O estruturalismo foi uma das primeiras escolas de pensamento dentro da psicologia científica. O teórico mais renomado foi E. B. Titchener, considerado seu fundador. Titchener foi aluno de Wundt em Leipzig (Alemanha), e ao retornar aos Estados Unidos, criou seu próprio sistema de psicologia, "[...] projeto que considerava tarefa fundamental da Psicologia, [...], a análise da consciência em seus elementos, na direção de determinar sua estrutura" (BARRETO; MORATO, 2008, p. 149).

Os psicólogos desse movimento estavam ocupados, como aponta Henneman (2002, p.21), em "estudar os fenômenos mentais através de uma minuciosa descrição analítica dos fenômenos da consciência". Nesse sentido, eles adotavam como método de estudo a introspecção (processo de auto-observação), que ainda segundo Henneman (2002, p.21): "exigia um longo treinamento no laboratório e atitudes cuidadosamente controladas de observação e relato".

Esse foi um dos pontos de crítica ao sistema de Titchener, pois, como argumentavam os críticos, à introspecção não consistia em um método seguro, capaz de garantir o status de cientificidade a psicologia. Ora, se uma das características básicas da ciência diz respeito à objetividade, o método adotado pelos estruturalistas não conseguia responder a tal exigência, já que se tratava de algo subjetivo, que envolvia relatos individuais, subjetivos de cada sujeito. Além disso, nem todas as descrições apresentadas pelos participantes do experimento estavam livres de imprecisões. Conforme Schultz e Schultz (2009, p.118): "mesmo os indivíduos do mesmo laboratório, observando o mesmo material de estímulo, muitas vezes, não conseguiam obter a mesma observação". Este é um dos problemas marcante no sistema de psicologia desenvolvido por Titchener, que o tornava limitado, constituindo-se em um contexto propício ao desenvolvimento de outras escolas de pensamento capazes de superar esse problema. 
O fato de ser uma ciência pura, não voltada aos problemas práticos da vida quotidiana, também contribuiu para que o sistema de psicologia adotado por Titchener fosse superado por uma nova escola de pensamento da psicologia, interessada nas aplicações dos conhecimentos dessa ciência às dificuldades da sociedade norte-americana. Contudo, é inegável a contribuição desse pensador para o desenvolvimento da psicologia como ciência.

\section{FUNCIONALISMO}

O funcionalismo surge nos Estados Unidos como oposição a escola de pensamento anterior. Embora adotando a consciência como objeto de estudo, os funcionalistas partem de outro enfoque sobre a consciência, dessa forma como observam Schultz e Schultz (2009, p.123): "o funcionalismo se preocupa com as funções da mente, em como ela é usada por um organismo para se adaptar ao seu ambiente". Sendo assim, o foco na estrutura ou composição da mente proposto pelo estruturalismo é substituído pela ênfase em suas funções.

Baseados na teoria darwiniana da evolução das espécies, os psicólogos funcionalistas tentaram fazer da psicologia um saber prático, para isso era necessário compreender o processo de ajustamento do indivíduo ao meio, ou seja, como ele se adaptava às situações da vida diária. Esse novo interesse da escola funcionalista logo ganhou o respeito e admiração do público (norte-americano) que visualizava a importância da psicologia na solução dos problemas sociais. Deste modo, a psicologia funcional ganha grande notoriedade, e a ênfase na aplicabilidade do conhecimento psicológico permitiu o surgimento, dentro da psicologia, de variadas áreas de atuação, como a psicologia da educação, forense, clínica, organizacional e outras. Todas voltadas para auxiliar a sociedade na solução de suas problemáticas (SCHULTZ; SCHULTZ, 2009).

Deste modo, como apontam Barreto e Morato (2008, p. 149), "por enfatizar o prático, o útil e o funcional, encontrou solo fértil no espírito pragmático americano, que, acolhendo a idéia (sic) evolucionista e a atitude funcionalista dela derivada, legitimou o próprio projeto da Psicologia funcionalista”.

Nessa direção, é importante também destacar o trabalho ampliado dos funcionalistas em relação ao método de estudo. Enquanto os estruturalistas 
utilizavam como método unicamente a introspecção, os funcionalistas complementavam o método introspectivo com "[...] outras técnicas de obtenção de dados: os testes psicológicos, a pesquisa fisiológica, os questionários e as descrições objetivas do comportamento" (BARRETO; MORATO, 2008, p. 152). O que "[...] contribuiu significativamente não só para as descobertas da Psicologia com relação aos fenômenos de aprendizagem, desenvolvimento e personalidade, mas também para o desenvolvimento da Psicologia aplicada como técnica [...]" (BARRETO; MORATO, 2008, p. 152).

Essas mudanças efetuadas pelo funcionalismo inverteram a ação da psicologia, tornando-a não mais uma ciência restrita ao universo acadêmico, conduzindo-a aos mais diversos contextos sociais, contribuindo, dessa forma, para a resolução dos dilemas da sociedade americana. Tal inversão possibilitou a ampliação do campo da psicologia, abrindo várias oportunidades de atuação para os psicólogos norte-americanos.

\section{BEHAVIORISMO}

O behaviorismo é outra escola de pensamento da psicologia que surge a partir da crítica ao funcionalismo e estruturalismo.

Apesar de o funcionalismo ter contribuído para que a psicologia alcançasse um reconhecimento na esfera social como uma ciência aplicada, deixando de ser um conhecimento meramente acadêmico ou intelectualizado de especialistas nas universidades, estendendo-se aos problemas práticos da vida cotidiana e inaugurando uma nova forma do fazer psicologia. A fragilidade em relação ao objeto de estudo dos funcionalistas, bem como a necessidade de tornar a psicologia uma ciência objetiva, fez com que o movimento fosse superado pela escola de pensamento fundada pelo psicólogo John B. Watson.

Tendo como base a teoria evolutiva de Darwin, a teoria objetiva e mecanicista da aprendizagem de Edward Lee Thorndike, além das técnicas de condicionamento (reflexos condicionados) de Pavlov (BARRETO; MORATO, 2008), Watson, em um artigo de 1913, com o título "Psicologia como os behavioristas" a veem, faz uma crítica às escolas antecedentes, rejeitando, sobretudo, o objeto de estudo (consciência) e os métodos utilizados para estudá-lo. 
$\mathrm{Na}$ visão de Watson, para a psicologia de fato tornar-se uma ciência, afastando-se definitivamente da tradição filosófica, era preciso abandonar a subjetividade presente na introspecção ${ }^{5}$, irrelevante para uma psicologia científica. Desse modo, rejeitava todo conceito mentalista, como sensação, mente, consciência, etc. E destacava, como objeto de estudo da psicologia o comportamento observável, tendo como método de estudo a observação com ou sem o uso de instrumentos, método de teste, o relato verbal e método de reflexo condicionado. Segundo Bock, Furtado e Teixeira (2002, p.45), "Watson, postulando o comportamento como objeto da psicologia, dava a esta ciência a consistência que os psicólogos da época vinham buscando", ou seja, "um objeto observável, mensurável, cujos experimentos poderiam ser reproduzidos em diferentes condições e sujeitos" (BOCK; FURTADO; TEIXEIRA, 2002, p.45). Em outros termos, o que esse pensador buscava era a construção de uma psicologia livre de concepções transcendentes ou metafísicas (como alma, mente ou consciência), capaz de prever e controlar o comportamento.

O behaviorismo, como apontam Schultz e Schultz (2009), apresenta divisões, o behaviorismo de Watson, o neobehaviorismo que abrange os trabalhos de Tolman, Hull e Skinner e o neo-neobehaviorismo incluindo os trabalhos de Bandura e Rotter. Os quais não abordaremos nesse momento, pois foge do escopo do nosso trabalho, ou seja, daquilo que nos propomos a discutir na temática apresentada.

A psicologia com a escola de pensamento behaviorista, portanto, deixa de ser a ciência que estuda a consciência ou processos mentais, e tornar-se uma ciência do comportamento. Nesse sentido, a psicologia assume uma nova conceituação, diferente da apresentada pela tradição filosófica (estudo da alma), bem como das escolas precedentes de estudo dos elementos da consciência ou estudo da função da mente, formuladas pelo estruturalismo e funcionalismo, respectivamente.

\section{GESTALT}

A gestalt é a escola da psicologia com origem na Alemanha, tendo como fundadores Max

\footnotetext{
${ }^{5}$ Conforme Schultz e Schultz (2009, p.85), introspecção é a "autoanálise da mente para inspecionar e relatar pensamentos ou sentimentos pessoais".
} 
Wertheimer, Kurt Koffka e Wolfgang Köhler. Essa escola de pensamento também surge em oposição às ideias anteriores na psicologia, sobretudo, ao pensamento wundtiano. Entretanto, é possível perceber certa aproximação entre as ideias defendidas por Wundt e algumas ideias que compõem o escopo da escola da gestalt, sobremaneira no seu interesse pela experiência consciente, mas com uma diferenciação, como aponta Schultz e Schultz (2009, p.344): "o enfoque da Gestalt na experiência consciente era diferente da abordagem de Wundt e Titchener, pois se concentrava em uma versão moderna da fenomenologia".

A psicologia da gestalt adota o princípio de que "o todo é mais que a soma de suas partes", isso significa que para os psicólogos da gestalt, o ser humano deve ser considerado em sua totalidade, uma visão holística. A percepção é um dos pontos mais relevantes nos estudos e pesquisas nessa escola de pensamento. Diversos estudos foram realizados por psicólogos com animais, na tentativa de verificar 0 processo de aprendizagem a partir da percepção de determinada situação. Segundo Bock, Furtado e Teixeira (2002, p.60): "o que o indivíduo percebe e como percebe são dados importantes para a compreensão do comportamento humano".

Nessa perspectiva, a gestalt, em oposição ao behaviorismo de Watson, parte da ideia de que o comportamento não pode ser estudado de forma isolada, como simples unidade de estímulo-resposta. De acordo com Bock, Furtado e Teixeira (2002, p.60), "na visão dos gestaltistas, o comportamento deveria ser estudado nos seus aspectos mais globais, levando em consideração as condições que alteram a percepção do estimulo". Isso significa que o comportamento é determinado pela forma como o indivíduo percebe as coisas. Nesse contexto, para os autores supracitados, "muitas vezes, os nossos comportamentos guardam relação estreita com os estímulos físicos, e outras, eles são completamente diferentes do esperado" porque acrescenta "entendemos o ambiente de uma maneira diferente da sua realidade" (BOCK; FURTADO; TEIXEIRA, 2002, p.62).

A psicologia da gestalt, de certa forma, representa um resgate daquilo que os behavioristas estavam tentando afastar da psicologia, o conceito de consciência. E, grosso modo, a psicologia nessa escola de pensamento pode ser definida como 0 estudo da percepção.

\section{PSICANÁLISE}


A psicanálise é uma escola de pensamento com características distintas das demais. Isso é visível principalmente quando se verifica o seu surgimento. Ao contrário das escolas anteriores, todas tendo como berço a universidade, a psicanálise não tem origem na academia, ela surge a partir dos trabalhos clínicos de seu fundador Sigmund Freud, na tentativa de trata das pessoas com problemas metais. Além disso, a psicanálise diferentemente das demais escolas, adotava como objeto de estudo o comportamento anormal, utilizando como método a observação clínica. Outro ponto que a diferencia das demais escolas de pensamento é o estudo conferido pela psicanálise ao fenômeno inconsciente.

Freud após a formação em medicina desenvolveu interesse no estudo do comportamento humano, especializando-se em psiquiatria. Mas, ele parte de uma visão diferente em relação à psiquiatria tradicional. Enquanto esta tentava explicar os distúrbios psicológicos como originários de problemas orgânicos, Freud aponta a origem dessas desordens como decorrentes de problemas no psiquismo, ou seja, muitos dos comportamentos desajustados tinham origem mental.

O sistema de psicologia Freudiano foi construído tendo como base suas experiências pessoais e no tratamento de seus pacientes. Nesse sentido, Freud, no decorrer dos anos, foi modificando a psicanálise a partir de suas observações clínicas, criando, ampliando e modificando conceitos e métodos.

Inicialmente empregava como forma de tratamento dos pacientes tanto o método hipnótico quanto o catártico. A experiência de Freud com Breuer, sobretudo no relato do tratamento de uma das suas pacientes, a famosa Anna O, permitiu a Freud a aprendizagem sobre o uso da hipnose no tratamento dos problemas mentais.

Uma influência importante no pensamento de Freud foi dado por Charcot. Freud estudou com Charcot em Paris. Ao tratar de uma paciente com histeria, Charcot destacou para Freud que o problema da paciente tinha uma origem sexual. Esta ideia foi marcante no pensamento de Freud e no desenvolvimento da psicanálise.

Utilizando o método de hipnose no tratamento dos pacientes, Freud logo observou que ele apresentava limitações. Primeiramente, porque, apenas proporcionava um alívio momentâneo dos sintomas dos pacientes e não a cura 
definitiva, além do mais, não eram todos os pacientes que conseguiam ser hipnotizados. Posteriormente adota outro método conhecido como livre associação ${ }^{6}$.

A tese do sexo, como fator determinante na origem da neurose, tornou-se central para Freud. Durante seu atendimento aos pacientes, "observou que a maioria das pacientes relatava traumáticas experiências sexuais vividas na infância", acreditando, "que as condições neuróticas não ocorreriam nas pessoas com vida sexual normal" (SCHULTZ; SCHULTZ, 2009, p.362).

Utilizando o método da livre associação, Freud notou que, em muitos casos, os pacientes chegavam a experiências dolorosas, as quais não conseguiam relatar. Para Freud, essa resistência funcionava como uma proteção em relação ao sofrimento emocional. Isso possibilitou a ele a descoberta do mecanismo de repressão ${ }^{7}$. Freud também utilizou como método de tratamento a análise dos sonhos que consistia na interpretação dos sonhos dos pacientes. Distinguindo-os em dois níveis: o conteúdo manifesto do sonho: que consiste no relato do sonho pelo paciente e o conteúdo latente: que corresponde ao valor simbólico do sonho, aquilo que só é desvendado por meio de análise.

Como mencionado no início, Freud instaura na psicologia um novo tópico, o inconsciente. Ele procura diferenciar o inconsciente da consciência, utilizando uma analogia do iceberg. Segundo Freud, a parte visível ou observável do iceberg corresponde à consciência, e a outra parte submersa e muito maior, o inconsciente. Dessa maneira, como aponta Teles (2006, p.48), "o homem, portanto, conhece apenas algumas de suas motivações, porque, a maioria delas tem raízes lançadas no inconsciente". Nesse sentido, a autora supracitada destaca os níveis de personalidades: o id, ego e superego. O primeiro corresponde aos instintos, ou seja, é a parte irracional; o segundo (o ego) é responsável por controlar os instintos do id, sendo a parte racional; o terceiro refere-se ao aspecto moral, a moralidade (TELES, 2006).

Outro ponto importante é a divisão feita por Freud dos estágios psicossexuais do desenvolvimento da personalidade: o estágio oral, do nascimento aos dois anos, tendo como fonte de estimulação a boca; o estágio anal, cuja fonte de prazer é o

\footnotetext{
${ }^{6}$ O método da livre associação foi formulado por Freud, após perceber que os outros métodos adotados no tratamento dos pacientes, como o hipnótico e catártico, não estavam dando resultados satisfatórios no tratamento dos mesmos. Através dessa técnica o paciente era estimulado a relatar livremente tudo àquilo que lhe vinha à mente.

${ }^{7}$ Segundo Schultz e Schultz (2009, p. 371) esse processo consiste em "barrar ideias (sic) inaceitáveis, memórias ou desejos do consciente, deixando-os operar livremente no inconsciente".
} 
anus; estágio fálico, por volta dos quatro anos de idade, cuja satisfação erótica envolve os órgãos sexuais, fase em que ocorre o Complexo de Édipo; o período de latência que vai até a puberdade, e logo em seguida, o estágio genital, fase em que o indivíduo busca a satisfação no outro.

A psicanálise como um sistema da psicologia traz uma definição diferenciada das outras escolas de pensamento, abordando o inconsciente como objeto de estudo dessa ciência.

\section{CONSIDERAÇÕES FINAIS}

Como foi possível observar ao longo de nossa discussão, a psicologia é uma ciência caracterizada por contrastes. Isso se deve ao fato de estar dividida em variados sistemas, cada qual tentando definir uma conceituação para essa ciência. $A$ psicologia no decorrer dos anos foi sendo modificada de acordo com as escolas de pensamento que foram surgindo. Desse modo, como verificado no texto, cada uma delas surgiu e ganhou notoriedade a partir da oposição a escola anterior.

Essas diversidades de posicionamentos dentro da psicologia provocam muitas discussões, sobretudo, por ser um ramo da ciência que não tem um objeto único de estudo, apresentando uma diversidade de visões de mundo, objetos e métodos. Provavelmente, seja em função desta pluralidade epistêmica e metodológica, que Bock, Furtado e Teixeira (2002) prefiram utilizar o termo Psicologias ao invés de Psicologia. Talvez esse seja realmente o termo mais correto, porque, estamos, na verdade, falando de várias psicologias, cada qual com objeto e métodos de estudos próprios.

Nesse sentido, surge uma questão não muito fácil de ser respondida: é possível uma unidade na psicologia? Ou seja, é possível unir todas essas visões divergentes sobre a psicologia, em um único conceito, definindo, portanto, tanto essa ciência quanto seu objeto de estudo?

Apesar de não termos abordado outras psicologias nesse trabalho como a psicologia cognitiva, evolucionista, etc. E diante dos argumentos apresentados, acreditamos ser difícil promover essa unidade na psicologia, porque, como apontado no texto às variadas posições dentro dessa ciência foram ganhando espaço a partir da oposição ao movimento anterior. Um fato a ser considerado é que a partir das 
escolhas das linhas terapêuticas, também chamadas de abordagem da psicologia estas relacionadas às concepções epistemológicas de cada linha de pensamento -, nota-se uma resistência entre os adeptos dessas formas de psicologias em abandonar suas posições iniciais e abraçar um novo sistema, representando um dos empecilhos para que isso ocorra. É possível perceber dentro das turmas do curso de psicologia essa divisão dos grupos em torno das abordagens. Os que adotam, por exemplo, a linha behaviorista ou comportamental, não dialogam com os da abordagem gestaltista, cada qual defende sua posição veementemente, assumindo, muitas vezes, uma função dogmática, que em muitas situações, pouco contribui para o desenvolvimento e crescimento da psicologia como ciência.

É nesse sentido, que acreditamos que a proposta de uma unidade na psicologia, como defendida pelos behavioristas no início deste movimento, seja algo impossível, uma vez que essa dispersão na psicologia é histórica, ou seja, está presente desde os primórdios de sua existência, mantendo-se ao longo dos anos, e apesar das alterações no objeto de estudo e metodologias com o surgimento das diferentes escolas de pensamento, o problema da unificação nessa ciência permanece sendo objeto apenas de debates, não existindo nenhum consenso entre as diversas perspectivas metodológicas, epistemológicas ou conceituais em prol da unidade na psicologia.

\section{REFERÊNCIAS}

Aranha, M. L. A; MARTINS, M. H. P. Filosofando: introdução à filosofia. São Paulo: Moderna, 2009.

BARRETO, C. L. B. T.; MORATO, H. T. P. A dispersão do pensamento psicológico. Boletim de psicologia, v. LVIII, n. 129, p. 147-160, 2008.

BOCK, A. M. B; FURTADO, O.; TEIXEIRA, M.L.T. Psicologia: uma introdução ao estudo de psicologia. São Paulo: Saraiva, 2002.

DESCARTES, R. Discurso do Método (Os Pensadores). São Paulo: Abril Cultural, 1987.

HENNEMAN, R. H. O que é psicologia. Trad. José Fernando Bittencourt Lomonaco. 22 ed.- Rio de Janeiro: José Olympio, 2002. 
SCHULTZ, D. P; SCHULTZ, S. E. História da psicopatologia moderna. Trad. Sonoe Murai Cuccio. São Paulo: Cengage Learning, 2009.

TELES, M. L. S. O que é psicologia. São Paulo: Brasiliense, 2006. 